\title{
The Complicated Digital Fandom: Empowerment and Exploitation of Fans in Digital Media Era
}

\author{
Zihan Wang \\ Department of Digital Humanities, Faculty of Arts \& Humanities, King's College London, London, UK \\ Email address: \\ wangzihan960714@outlook.com

\section{To cite this article:} \\ Zihan Wang. The Complicated Digital Fandom: Empowerment and Exploitation of Fans in Digital Media Era. Humanities and Social Sciences. \\ Vol. 8, No. 2, 2020, pp. 45-50. doi: 10.11648/j.hss.20200802.11
}

Received: February 18, 2020; Accepted: March 5, 2020; Published: March 17, 2020

\begin{abstract}
Over the past several decades, the once despised fans have been introduced to the central stage of audience study, challenging people's stereotype about fans. Fans are considered as the most active and visible audiences since they are active producers rather than passive consumers. With the pervasiveness of the digital media, fans are provided with more opportunities to engage with the media production and challenge the authority of media industry. However, there are still some scholars argue that fans in digital era are prone to be exploited by media industry as free labor. These two contradictory aspects illustrate the main characteristics of fans in digital media era. This research aims to explore the reconfigured relationships between fans and professional media producers, critically discussing the extent to which fans are empowered and exploited in the digital media era. The analysis in this paper is organized from three main aspects: first, the transformation of fans' images in the ever-changing media landscapes is illustrated, emphasizing the trend that fans are increasingly considered to be more active and influential in the media production process; second, the ways that fans engage with media production in the digital media era are explored in details, which supports the opinion that fans are empowered in digital media era; third, the emerging exploitations of fans online practice are demonstrated by employing the concept of free labor. By critically discussing both the empowerment and exploitation of fans in digital media era, in this paper, it is concluded that although the increasing productivity and influence of fans imply the reconfigured relationships between fans and media producers, the emerging exploitation of fans' free labor should not be ignored which indicates that the power discrepancy between fans and media producers still exists. The empowerment and exploitation of fans in digital media era should not be considered as a zero-gum game. Since the digital fandom is more complicated than before, the binary opposition between empowerment and exploitation should be revisited and revised. Within the context of the emerging digital economy, fans and media producers are continuously negotiating with each other.
\end{abstract}

Keywords: Fans, Digital Fandom, Digital Media, Participatory Culture, Free Labor

\section{Introduction}

Over the past 30 years, many scholars have conducted in-depth researches on fans from different theoretical perspectives such as political economy, sociology, psychology and cultural anthropology. It has been gradually acknowledged that fans are active audiences rather than hysterical crowd.

The development of digital technologies has imposed a profound impact on fandom, "blurring the lines between producers and consumers, creating symbiotic relationships between powerful corporations and individual fans, and giving rise to new forms of cultural production" [1]. These emerging phenomena have aroused debates on whether fans are empowered or disempowered in the digital media era. How to understand fans and their practices in digital media era has aroused heated discussions.

With the development of digital media technologies, fans are provided with more potential opportunities to engage with the process of media production directly or indirectly, challenging the dominance of professional media producers in the media production and dissemination processes. However, it is also the advanced digital technology that make fans be exploited in a more invisible way. These two main controversial aspects have portrayed the main characteristics of fans in digital media era, which shows the reconfigured and dynamic relationships between fans and media producers. 
This paper seeks to critically discuss the relationships between fans and professional media producers in the digital media realm. After giving a brief literature review of fans' images in different media landscapes, the extent to which fans are empowered or disempowered (exploited) in the digital media era will be illustrated separately.

\section{The Transformation of Fans' Images in Different Media Landscapes}

Fans research has achieved many ground-breaking results, but there is currently no clear and unified definition of "fans". Many scholars have attempted to conceptualized fans by distinguishing them from normal consumers.

Before the $1980 \mathrm{~s}$, fans were considered as deviants [2]. The term "fans" often refers to those who are enthusiastic, emotionally and commercially invested follower of popular culture objects. Almost throughout the twentieth century, fans were often portrayed as the "obsessed individual", the "hysterical crowd" and the "brainless consumers" who were immature, socially inept and addicted to the fictional worlds, escaping from their real lives. In addition, they were likely to be associated with some pejorative connotations due to its "uncompromising religious zeal and mental instability" [3].

However, these stereotypes of fans were challenged since fans' power and the importance of consumption have been recognized. The once despised fans have been introduced to the central stage of audience research because the cultural and socio-logical study of fans is important for people to understand media audiences.

In today's media-saturated environment, we are all fans to some extent. According to Gray, audiences are divided into three types: fans, anti-fans and non-fans [2]. Among all kinds of audiences, fans are relatively most involved in media consumption, which attracts considerable attention from scholars. Sandvoss describes fans to be all consumers and users who develop a continuing and meaningful emotional relationship with cultural texts and objects [4]. However, Jenkins argues that it is not enough to define the characteristics of fans by using the word like admiration or worship merely. Fans are not only passive consumers of specific programs, but also the active producers who can develop such viewing behavior into cultural practices.

\subsection{Fans in the Mass media Era}

In the mass media era, fans are taken for granted as passive consumers since most of them lack direct access to cultural production. Fans are defined as 'cultural idiots' by the Frankfurt School. However, this kind of opinions have been challenged by the advent of concepts such as "textual poachers" and "nomadic readers" which are originally proposed by Michel de Certeau [5].

De Certeau claims that readers are active and describes their active reading as "poaching", which indicates that readers will take away useful and enjoyable things. He points out that readers are also nomads who move among different texts, appropriate new materials and create new meanings. Jenkins deploys these two concepts to describe fans since they can employ diverse interpretive strategies when engaging with their favorite media texts actively. Many of them even go beyond the close reading and interpretation of the existing media content, taking advantage of the semiotic raw materials offered by existing media content such as TV shows, movies and books to produce new cultural products which suit their needs and interests. In other word, whether being portrayed as "poachers" or "nomads", fans should be considered as "active producers and manipulators of meaning" [6] rather than passive consumers.

In addition, some scholars point out that fans can even "use their interpretive power to actively subvert, distort, and even reimagine mainstream media content to suit their own needs and desires" [7]. In this term, fans can challenge the "interpretive authority of media institutions in the process" [7]. For example, in the late 1970 s, a female fan wrote a fan fiction of Star Trek. Since she was unsatisfied with the relatively conservative female images in the film, she added a talented, brave and honest female character to support feminism. This example supports the idea that fans can intervene in the circulation of textual meaning, specifically at level of reception, resisting the mainstream ideology [8].

In conclusion, there is a trend that fans' initiative and creativity are emphasized, and the importance of fans' power have been increasingly recognized.

\subsection{Fans in the Digital Media Era}

With the pervasiveness of more advanced digital technologies, especially the Internet, the interaction between fans and media producers has been deeply altered.

On the one hand, "the expansive, malleable nature of the internet and the declining cost of computers have allowed fans to easily extend their media experiences beyond the reception of the original text" [7]. The Internet provides technical support for the rise of user-generated content, facilitating the supposed "democratization of productivity". On the other hand, an increasing number of social media platforms provide fans with more opportunities to have a direct interaction with media producers. Therefore, fans are more likely to engage with the original production of media content and affect media producers' decision making [7], profoundly challenging the top-down tyranny of media producers.

In sum, fans are often considered to be more productive in the digital media era than before, obtaining more resources and integration within the digital media landscape. However, Bird argues that the sanguine views which celebrate the supposed empowerment of fans may raise some misunderstanding of their actual impact on media industry [9].

Although some fans revel in their empowerment and new opportunities brought by advanced digital technology, there are still some scholars worry about the "digitally enabled encroachment of corporate power into every space of fandom" [10]. These scholars propose that in the digital media era, fans are prone to be exploited by the media corporations because fans input huge amounts of labor that is commercially 
beneficial but rarely receive compensation. Since the digital fandom is complicated and contradictory, in the following sections, whether fans have been empowered in the digital media era will be critically discussed.

\section{Empowerment of Fans}

In digital media era, the boundary between consumers and producers has been increasingly blurred. The synergies between mass media and the Internet have transformed the way audiences interact with media producers [11]. Specifically, fans are provided with more opportunities to engage with the process of media production directly or indirectly, which has exerted profound impact on the production of media content. In the following sections, the ways that fans engage with media production will be illustrated in details. These emerging fans online practices indicate the empowerment of fans, challenging the authority of professional media producers.

\subsection{Fans' Participatory Media Consumption}

The surge of interactive media, especially the social media platforms like Twitter, Facebook and Instagram, encourages fans to climb out of the couch [12] to provide instant feedback to media producers and other audiences without management filters. Fans have gained greater possibility to interact with other fans and even with media producers directly and instantaneously, while in mass media era, the communication is linear in most cases.

For media producers, fans' feedback can help them catch up with the market trends and preferences. Since fans have more choices in the digital media era, media producers have been pushed to modify their products and strategies in response to fans' demands for the purpose of higher profit. For example, the proliferation of talent shows such as "Produce 101", a program aims to create an idol group based on fans' voting and feedback, has been deemed to show the rich potential in allowing fans to become a part of the creative process. The development of the talent show regularly features 'meta-discourse on media production and themes, responds to viewers' feedback and preferred narratives and shares the creation of meaning with the audience' with the result that 'viewers feel that their concerns are recognized and often directly addressed by the show's official creative team' [13].

The typical feature of fan culture is participation. "Participatory cultural transforms the experience of media consumption into the production of new texts, indeed a new culture and a new community" [6]. Participation and sharing are bound to require fans to form a community. In the mass media era, the scale of the fan communities and the frequency of fan activities are greatly limited, since offline fan communities are very difficult to set up. With the pervasiveness of digital technologies, it is more convenient for fans to set up their online communities and interact with each other.

The unity of fans makes them have greater initiative and influence on media industry. "The close-knit communities of fans can offer direct challenges to existing authority. Fans can be mobilized to press producers and media corporations for change (or, as is more often the case, to prevent changes from coming about in a favourite media text)" [7]. In other word, with the development of interactive media, fans are empowered in the process of consuming media content, since they can interact with media producers to express their opinions directly, which can impose significant impact on media producers' strategies and decisions.

\subsection{Fans as "Produsers"}

In the digital media era, fans are considered to be more productive since they not only have greater influence on media industry, but also become the "prosumers".

According to Sullivan [7], "we are witnessing a unique tipping point in human society, where the ubiquity of networked computing in the most advanced economies of the world is creating a new mode of production by transforming passive information receivers into engaged information producers". In the 1960s, Marshall McLuhan proposed that the development of computer and Internet would affect not only the media production, but also the media consumption. Consumers will become producers after mastering digital technologies.

Toffler proposed the concept "prosumer", indicating that the boundary between producers and consumers would be blurred gradually [14]. He predicted that after the mass production of standardized products reached the market saturation, mass customization would occur. Since the involvement of consumers is required by customization, consumers, therefore, become producers to some extent. Bruns then transformed the word "prosumer" into "produser" which represents the combination of "producer" and "user" [15]. There is no doubt that in the digital media era, fans are typical "produsers". Fans are still the most loyal consumers in the first place, but their productivity is no longer limited to textual poaching like reinterpreting and commenting.

In the digital media era, fans can directly engage with the production and distribution of their own media content. The development of digital technologies provides fans with diversified and easy-to-use tools, facilitating the richness of fan creativity. Except for the flourished online fan fictions, visual arts have been especially facilitated by the advanced digital technologies. Social media platforms like YouTube, Tumblr and Twitter have fostered the prospect of these creativities within fandom to be spread more easily, quickly and widely than before, potentially reaching more audiences. The Internet is considered as a tool for self-empowerment because the fan subculture groups such as subtitle groups can also be the knowledge producers on the Internet, breaking the monopoly of knowledge and challenging the institutional producers.

The new modes of fans' online engagement indicate a "potential liberation from the hegemonic control of the context" [7]. Fan production represents a new cultural production pattern which directly challenges the official authority in a non-profit and shared way, posing a threat to 
traditional business models [16]. This forces the media industry to recognize fans' power. However, we should admit that not all fans are "produsers". Only those in a relatively higher socio-economic status can participate in the production of cultural products since they have more resources and higher media literacy.

In summary, these new modes of fans practices prove that fans are becoming more influential and productive, gaining new opportunities to challenge the dominance of media industry. In essence, the empowerment of fans in digital media era indicates the reconfigured relationships between producers and consumers in the digital economy.

\section{Exploitation of Fans' Free Labor}

In the previous section "Empowerment of fans", it has been illustrated that fans are more influential and productive than before, challenging the official authority of media industry. However, there are still some scholars argue that fans are prone to be exploited by media industry in digital media era. The critical analysis which refers to the unpaid work on the part of participants involved in the digital media has been the dominant theme of recent media researches [17].

Tiziana Terranova deploys the concept "free labor" to define this phenomenon. Free labor is considered as "an important, yet unacknowledged, source of value in advanced capitalist societies" [18]. This kind of labor is "simultaneously voluntarily given and unwanted, enjoyed and exploited' and on the internet included "building web sites, modifying software packages, reading and participating in mailing lists and building virtual spaces" [18]. Compared with the prevailing assumptions of "liberation" and "empowerment" in the debate about the social consequences of digitization, the concept of "free labor" indicates an anxiety.

Fans' online practices are characterized as "free labor" which is prone to be exploited by media industry in the digital context, since most of the practices are beneficial for media producers but rarely being compensated. In digital capitalism, "the generation of value is increasingly produced outside capital's organization of labor". Some scholars argue that fans should be compensated for their practices which are exploited by corporations to generate profits. In the following sections, how fans' online practices can be exploited by media industry in a more invisible way will be demonstrated from three main aspects separately.

\subsection{Fans Online Interaction as a Part of Marketing Strategy}

Fan's online interactions may be exploited as a part of marketing strategy. It is demonstrated that fans can affect media producers' decisions by providing instant feedback. Many fans conceive that their feedback can exert some sort of influence on media producers. It seems that producers will be pushed to modify their products and strategies in response to fans, while for media producers, fans' feedback can be exploited to save them from implementing expensive market research. Furthermore, since fans are the most active audiences and their discussions about the media products can attract more ordinary audiences, some scholars express their concern that this kind of online participation might be employed by media producers as a marketing strategy to publicize their media products, which in effect save marketing costs [12].

The feeling of participation makes fans believe that they have played an active and creative role in producing the media products, which can increase their participation-based loyalty. These seemingly effective interactions between fans and media producers can involve an "illusion of reciprocity", which is employed to hide "an empty relationship that encourages fans to believe that they have an input when they actually have little impact on the TV industry or the texts it produces" [19].

In fact, most fans' attempts to alter media producers' decisions have failed, which implies their actual impact on media producers may be trivial and powerless. In other words, fans in digital media do obtain more power to challenge the media producers, but the result may not always as they imagine. Therefore, Tulloch and Jenkins propose that fans are "powerless elite". Indeed, media producers are becoming very adept at disciplining fan "produsage" by imposing some terms of service on fans activity [9]. For example, some supposedly interactive nature of many authorized websites which refers to allowing fans to upload their own views or user-generated content can just provide fans with a "false sense of personal agency", since the fan practices are controlled by limitations formulated by producers. This does not mean that fans have no influence on media production, but rather that such processes of influence may be more powerless than assumption.

\subsection{Privacy Data Are Exploited for Profit}

The data provided by fans' online practices are being sold to advertisers for profit. The argument that the data has been sold for profit predates the digital age. Smythe originated this argument in 1977, proposing that television audiences perform labor which is sold to advertisers as a commodity while without any financial compensation [20]. One of the core arguments around this phenomenon is the relation between free labor and the production of value.

This argument has become rather popular and has been extended into the digital media realm. In the digital media era, data mining on the social media platforms creates a new form of exploitation of the free labor performed by fans even all the users. The data generated by fans' online communicative practices can be sold to advertisements, and then big corporations like Facebook and Twitter can gain profits. In other words, fans provide free labor and generate surplus value which is captured by capital.

The exploitation of the free labor discussed above is always be ignored, since "it doesn't feel, look, or smell like labor at all. This digital labor is much akin to those less visible, unsung forms of traditional women's labor such as child care, housework, and surrogacy" [21].

\subsection{Monetized Fans-generated Content}

Media producers benefit from fans online creativity by 
monetizing user-generated content for promotion. Fans creativity has "at least indirectly benefited the powerful corporations Jenkins refers to (which, of course, is why so many of them are now intent on directly benefiting)" [10].

Take subtitle groups as an example, their free labor has help commercial corporations explore and develop new overseas markets to increase their profit [22]. This kind of non-profit creativities have become "increasingly monetized by corporations, transforming into essentially free labor" [7]. The subjectivity of fans is expropriated by capital. Capital controls most of the details of the media production, distribution process and determines how to absorb audience's labor. In addition, the capacity of media corporations for commercial exploitation has been greatly facilitated in the digital context than before.

However, when considering the exploitation of fans online creativity, the situation may be more complicated. On the one hand, fans are subject to a non-economic output-to-input mechanism [22]. The economic compensation cannot be deployed as the only measure which is used to evaluate whether fans are exploited. Fans continually invest their emotions and perform labor since they can obtain pleasures and satisfactions which can be considered as emotional compensation. Most of the online practices are not profit-driven, since fans enjoy the process of creativity and they are not forced to earn their own living by these products.

On the other hand, this kind of free labor ideally suits fans' anticommercial requirement because they fear that they will be sued by media producers for copyright violation. "The general understanding is that if no money is exchanged, the copyright owners have no reason to sue because they retain exclusive rights to make money from their property" [23]. In the legal minefield of copyright law, free labor exploited by media industry indicates a kind of negotiation between fans productive practices and commodity culture takes place. In other words, the form of "free labor" also contributes to the flourish of fans online creativity by evading copyright restrictions.

\section{Conclusion: The Reconfigured Relationships Between Fans and Media Producers}

In the digital media era, as Jenkins proposes, fans practices have generated more significant influence. "Convergence culture describes a moment when fans are central to how culture operates. The concept of the active audience, so controversial two decades ago, is now taken for granted by everyone involved in and around the media industry" [24].

A dominant theme of recent critical analysis of digital fandom is whether fans are empowered in the digital media era. The core of the discussion is the relationship between fans and media producers. To some extent, fans are empowered since they can not only influence media producers' decision more directly and instantaneously, but also have become "produsers", potentially undermining traditional hierarchies of expertise and authority.

However, the optimistic assertion may ignore that the power discrepancy between fans and media producers still exists and can make fans powerless. There are still some scholars arguing that fans are prone to be exploited in digital media era. Acknowledging the remaining power inequality between fans and media producers can avoid unilaterally celebrating the alleged "democratization of productivity".

Essentially, this emerging debate indicates the reconfigured relationships between fans and media producers. The complexity of fans practice requires an avoidance of univocally productive or exploitive stances. The binary opposition between empowerment and exploitation should be revisited and revised. The actual fans in digital era are complicated and contradictory. Although fans in digital era are more significant than before, the exploitation of fans practices should be acknowledged.

In addition, from the perspective of fans' subjective feelings, their online participation and productivity are not profit-driven in most cases. More emotional factors are involved in their participatory practices. Although, the fact is that they are exploited by the media industry in a more invisible way, they still enjoy the process of engagement and believe that their participation can create some sort of influence. In this way, whether being exploited is not so important for fans.

The reconfigured relationship between fans and media producers should not be regarded as a zero-sum game. Fans and media producers are continuously negotiating in the digital context. As media producers seek to benefit from the fans practices engendered by the advance digital technology, fans are provided with more opportunities to enter the "corporate walled garden" [10], participating in the media production. Therefore, within the digital economy context, empowerment and exploitation of fans "coexist and interpenetrate one another" [12]. This supposedly "reciprocal process" may provide a new model of "negotiated sharing of productive power" [10] for the reconfigured producer-consumer relationships.

In the future research, the power balance between fans and media producers, "the space between marketing concept and semiotic democracy" [10] can be explored to further disentangle the reconfigured relationships between fans and media producers.

\section{References}

[1] Bennett, L. (2014). Tracing Textual Poachers: Reflections on the development of fan studies and digital fandom. The Journal of Fandom Studies, 2 (1), 5-20.

[2] Gray, J. (2008). Television Entertainment. New York: Routledge.

[3] Hayashi, A. E. (2018). Musicking, discourse, and identity in participatory media fandom.

[4] Sandvoss, C. (2005). 'Challenging boundaries: fans and cultural industries', in Oakley, K. \& O'Connor, J. (eds.). The Routledge companion to the cultural industries, pp. 357-370. Oxon \& New York: Routledge. 
[5] Certeau, M., \& Rendall, Steven. (1984). The practice of everyday life. Berkeley: University of California Press.

[6] Jenkins, H. (1992). Textual poachers: Television fans and participatory culture. Cambridge: Cambridge University Press.

[7] Sullivan, J. (2013). Media audiences: effects, users, institutions, and power. SAGE Publications.

[8] Gray, J., Harrington, L., \& Sandvoss, C. (eds) (2007). Fandom: Identities and communities in a mediated world. New York: New York University Press.

[9] Bird, S. E. (2011). Are we all produsers now? Convergence and media audience practices. Cultural Studies, 25 (4-5), 502-516.

[10] Pearson, R. (2010). Fandom in the digital era. Popular Communication, 8 (1), 84-95.

[11] García Avilés, J. A., (2018). Roles of audience participation in multiplatform television: From fans and consumers, to collaborators and activists.

[12] Andrejevic, M. (2008). Watching television without pity: The productivity of online fans. Television and New Media, 9 (1), 24-46.

[13] Sharma, R. (2013). Community clip show: Examining the recursive collaboration between producers and viewers of a postmodern sitcom. The Journal of Fandom Studies, 1 (2), 183-199.

[14] Toffler, A. (1980). The third wave. London: Collins.
[15] Bruns, A. (2006). Towards Produsage: Futures for User-Led Content Production. In: Sudweeks, F., Hrachovec, H., Ess, C. (eds.) Proceedings: Cultural Attitudes towards Communication and Technology, pp. 275-284. Murdoch University, Perth.

[16] Yang, L. (2009). Fans, affective economics and new media. Social Science Front, 2009 (7), 173-177.

[17] Beverungen, A., Böhm, S. and Land, C., (2015). Free labour, social media, management: Challenging Marxist organization studies.

[18] Terranova, T. (2004). Network culture: Politics for the information age. London; Ann Arbor, MI: Pluto Press.

[19] Williams, R., (2010). Good Neighbours? Fan/producer relationships and the broadcasting field. Continuum, 24 (2), pp. 279-289.

[20] Wittel, A. (2014). Digital labor: the internet as playground and factory.

[21] Scholz, T. ed., 2012. Digital labor: The Internet as playground and factory. Routledge.

[22] Yang, M. (2012). Fansub group and transnational communication of Japanese animation: Paradox of audience initiative. Journalism \& Communication, 2012 (5): 48-55.

[23] Hellekson, K. (2009). A Fannish Field of Value: Online Fan Gift Culture. Cinema Journal, 48 (4), 113-118.

[24] Jenkins, H. (2006). Fans, bloggers, and gamers: Exploring participatory culture. nyu Press. 